Please do not remove this page

RMIT

UNIVERSITY

\title{
Micromechanical finite element analyses of fire-retardant woven fabric composites at elevated temperatures using unit cells at multiple length scales
}

Li, Hongzhou; Kandare, Everson; Li, Shuguang; Yongchang, Wang; Kandola, Baljinder; Myler, Peter;

Horrocks, A.

https://researchrepository.rmit.edu.au/esploro/outputs/9921858139301341/filesAndLinks?institution=61RMIT_INST\&index=null

Li, H., Kandare, E., Li, S., Yongchang, W., Kandola, B., Myler, P., \& Horrocks, A. (2012). Micromechanical finite element analyses of fire-retardant woven fabric composites at elevated temperatures using unit cells at multiple length scales. Computational Materials Science, 55, 23-33.

https://doi.org/10.1016/j.commatsci.2011.11.019

Document Version: Accepted Manuscript

Published Version: https://doi.org/10.1016/j.commatsci.2011.11.019

Repository homepage: https://researchrepository.rmit.edu.au

(C) 2011 Elsevier B.V.

Downloaded On 2023/04/26 22:05:08 +1000 
Thank you for downloading this document from the RMIT Research Repository.

The RMIT Research Repository is an open access database showcasing the research outputs of RMIT University researchers.

RMIT Research Repository: http://researchbank.rmit.edu.au/

\section{Citation:}

Li, H, Kandare, E, Li, S, Yongchang, W, Kandola, B, Myler, P and Horrocks, A 2012, 'Micromechanical finite element analyses of fire retardant woven fabric composites at elevated temperatures using unit cells at multiple length scales', Computational Materials Science, vol. 55, pp. 23-33.

See this record in the RMIT Research Repository at:

http://researchbank.rmit.edu.au/view/rmit:15492

Version: Accepted Manuscript

Copyright Statement: (C) 2011 Elsevier B.V.

Link to Published Version:

http://dx.doi.org/10.1016/j.commatsci.2011.11.019 


\section{Micromechanical Finite Element Analyses of Fire-Retarded Woven Fabric \\ Composites at Elevated Temperatures using Unit Cells at Multiple Length Scales}

Hongzhou Li $i^{\mathrm{a},{ }^{*}}$, Everson Kandare ${ }^{\mathrm{b}, \mathrm{c}}$, Shuguang $\mathrm{Li}^{\mathrm{d},{ }^{*}}$, Yongchang Wang ${ }^{\mathrm{e}}$, Baljinder K. Kandola ${ }^{\mathrm{b}}$, Peter Myler $^{\mathrm{b}}$, A. R. Horrocks ${ }^{\mathrm{b}}$

${ }^{a}$ Ningbo Institute of Material Technology and Engineering, Chinese Academy of Sciences, Ningbo

$$
\text { 315201, China }
$$

${ }^{\mathrm{b}}$ Institute for Materials Research and Innovation, University of Bolton, BL3 5AB, United Kingdom

${ }^{\mathrm{c}}$ School of Aerospace, Mechanical and Manufacturing Engineering, RMIT University, Melbourne,

\section{Australia}

${ }^{\mathrm{d}}$ Department of Mechanical, Materials and Manufacturing Engineering, University of Nottingham, Nottingham, NG7 2RD, United Kingdom

${ }^{\mathrm{e}}$ School of Mechanical, Aerospace and Civil Engineering, University of Manchester, Manchester, M60 1QD, United Kingdom

Computational Materials Science

\section{*Corresponding authors}

Tel: +8657486685802

Fax: +8657486685802

E-mails: lihz@nimte.ac.cn; shuguang.li@nottingham.ac.uk 


\begin{abstract}
This paper presents a micromechanical Finite Element (FE) model developed to predict the effective mechanical properties of glass fibre-reinforced (woven fabric) polymer composites with/without fire retardant particulate additives at elevated temperatures. The elevated mechanical properties of glass fibrereinforced epoxy composites with/without fire retardants were predicted using three unit cells of varying length scales in micromechanical FE analysis. Theoretically predictions of flexural behaviour of these fibre-reinforced polymer composites at elevated temperatures were satisfactorily validated against experimentally measured data. The numerical model developed herein was then used for the prediction of other mechanical properties of fibre-reinforced polymer composites that would have been difficult to collect at elevated temperatures. Micromechanical FE models such as the one contained in this paper are useful to architectural engineers as they can be used to guide the design and qualification of new engineering composites that satisfy stringent Building codes in fire prone engineering applications.
\end{abstract}

Keywords: Glass fibre-reinforced composites; Mechanical properties; High temperature properties; Finite element analyses; Multi-scale modelling 
Due to the thermal degradation, depolymerization, and the subsequent decomposition of the polymer matrix in fibre-reinforced polymer (FRP) composites, their utilization in fire prone structural engineering applications is limited. When exposed at elevated temperatures $\left(50^{\circ} \mathrm{C}<\mathrm{T}<200^{\circ} \mathrm{C}\right)$, polymer matrix resin systems tend to soften due to their intrinsically low glass transition temperature, $T_{\mathrm{g}}$. At temperatures similar to those created by fire $\left(\mathrm{T}>300^{\circ} \mathrm{C}\right)$, most polymer matrix systems decompose to give volatiles and solid char with negligible load carrying capacity. The volatiles produced during the flaming combustion of most resin matrices are dense and toxic causing smoke inhalation related problems to affected people as well as fire fighting crews. Dense smoke also makes it difficult for fire survivors to escape the fire thereby increasing fatalities. The structural integrity of engineering composite structures has also been demonstrated to be dependent on the composite resisting deformation and failure, rather than on the avoidance of flaming combustion [1]. Therefore, it is imperative to consider thermal softening of the polymer matrix as the governing process that dictates the fire structural performance of polymer composites.

However, while it is important to design composites that have a high fire safety rating (e.g., long time-to-ignition, low flaming intensity and low volume of volatiles), it is also critical to understand the thermo-mechanical behaviour of these composites at elevated temperatures where resin softening may cause catastrophic structural collapse. Many composite structures contain resin systems modified by fire retardants in order to improve their fire safety ratings. While fire retardants have been shown to significantly improve fire reaction properties of fibre-reinforced polymer composites at high temperatures $\left(\mathrm{T}>300^{\circ} \mathrm{C}\right)$, their effect on the mechanical properties of the composites at elevated temperatures is not fully understood. For this reason, there is need to experimentally and theoretically investigate the thermomechanical behaviour of composites at elevated temperatures $\left(50^{\circ} \mathrm{C}<\mathrm{T}<200^{\circ} \mathrm{C}\right)$.

Fire retardant additives are often mixed together with resin systems in order to improve the fire reaction properties of the later when used in the fabrication of the fibre-reinforced polymer composites. Compared to structural FRP composites without fire retardant additives, fire-retarded composites have been shown to have better fire resistance [2]. The improvement in fire resistance of FRP composites 
containing fire retardants is attributed to: 1) the retarded heat conduction into the laminate (e.g., lower rate of temperature increase), 2) the reduced rate of heat transfer within the laminate and 3) an increase in the amount of residual char following exposure at high temperature environments. While fire retardant additives may improve the fire performance of flaming structural FRP composites, their effect on the thermo-mechanical behaviour of the composites prior to ignition is not fully understood. Due to wide variations in composite constituent (fibre, resin and additives) volume fractions, fibre arrangement and orientation, a large number of experimental tests should be performed before a composite material is certified for use in fire prone applications. In addition to being specific to a particular structure, these experimental tests are laborious and costly, hence it is desirable to develop modeling techniques that have capabilities to predict the thermo-mechanical properties of structural composites with/without fire retardant additives at elevated temperatures.

There have been extensive theoretical (analytical and numerical) modeling studies of mechanical properties of structural composites without fire retardant inclusions at both ambient temperature and elevated temperatures [3-11], however, such studies are limited for FRP composites that containing fire retardants. Bai et. al. [3-5] derived analytical equations to obtain the stiffness of E-glass fibre reinforced polyester composites containing no fire retardant additives during exposure at elevated temperatures under uni-axial loading conditions. However, these researchers were unable to include the effects of voids in the derivation of their analytical models. Gibson, Mouritz, Feih and their co-workers [6-11] presented thermo-mechanical models to calculate the degradation in compression and tensile strength, and time-to-failure of woven glass/vinyl ester laminates exposed to one-sided radiant heating by fire. Their models can be used to calculate the compressive and tensile softening, and time-to-failure of glass fibre-reinforced polymer composite structures without fire retardants when exposed to fire. Although the analytical and numerical models presented in literature [3-11] are able to give an insight into the effects of a number of major variables (e.g., mass loss rate, volume fractions of composite constituents and effect of fire intensity) on some mechanical properties when FRP composites are exposed at elevated temperatures, their general applicability is limited due to the simplicity in material behaviour assumed. For example, when a composite laminate is exposed at elevated temperature, the thermal-induced damage 
progressively increases towards the exposed surface; e.g., the damage cannot be simply described using a two-layer model adopted by Gibson, Mouritz and co-workers [6-9]. In addition, the models developed by Bai, Gibson, Mouritz, Feih and co-workers [3-11] are generally not capable of predicting the evolution of mechanical properties for specimens loaded under multi-axial conditions. The rapid increase in computer power and computational modelling capabilities in recent years, have allowed the development and subsequent application of micromechanical-based FE methods to predict the response and behaviour of polymer composites with inherent multi-scale microstructures (e.g., FRP composites containing microparticulate additives) when exposed at elevated temperature.

Modern composites are often made of woven fabric wherein yarns of unidirectional fibres are interwoven into particular patterns such as plain, twill and various other types of harness satin weaves. While woven patterns are diverse, there is a common feature among them all - their periodic regularity. This generality offers a convenient opportunity for researchers to use micromechanics in order to model laminate structures by taking advantage of their inherent symmetry. In this approach, the composite material is idealized as a patterned array of identical cells, often referred to as unit cells at a micro- or mesoscopic scale [12-21]. The pattern in which unit cells are arranged can be described through one, or a combination of more, of three basic geometric symmetries: translation, reflection and rotation. By applying these geometric symmetry transformations, different unit cells can be obtained even from the same pattern [22]. For micromechanical Finite Element (FE) modelling of woven composites, three different unit cells derived from the inherent multi-scale geometries were used in this work. These three unit cells referred to as Unit Cell 1, Unit Cell 2 and Unit Cell 3, represent the modified resin matrix, the cross-section of a yarn and the woven fabric impregnated with resin, respectively. All these unit cells are based on the use of translational symmetry transformations only. The advantage of using this approach is that each of these established unit cells can be subjected to arbitrary combinations of macroscopic stresses or strains using a single set of boundary conditions. The use of reflectional and/or rotational symmetries results in unit cells for which analyses under individual macroscopic stress or strain components may require different boundary conditions [23]. Following the combination of these unit cells, the effective mechanical properties of a glass fibre-reinforced epoxy resin matrix composite 
with/without fire retardant additives at elevated temperatures were predicted. Theoretically predicted mechanical properties were validated against experimentally measured flexural data collected at elevated temperature.

\section{Finite Element Model: Elevated Temperature Analysis of Composites}

In this paper, a micromechanical FE model has been developed to predict the response of glass fibre-reinforced polymer composite laminates with/without fire retardant additives subjected to a combination of mechanical loading and elevated temperature $\left(\leq 150^{\circ} \mathrm{C}\right)$ exposure. The inclusion of particulate fire retardant additives in polymer matrices has been shown to significantly alter the mechanical properties of the cured resin and their corresponding fibre-reinforced composites [2]. Before one can investigate the overall effect of particulate additives on mechanical properties of fibre-reinforced polymer composites, it is logical to consider; first, their effect on a single constituent - the resin matrix. Once the mechanical behaviors of fire-retarded resins have been established, the properties of resinimpregnated fibre bundles can then be interrogated. Finally, the resin impregnated and interwoven fibre bundles can be investigated in order to allow the prediction of thermo-physical properties of fire-retarded FRP composites.

In Unit Cell 1, the effect of fire retardant particle inclusion at various volume fractions on the mechanical properties of the polymer resin is considered. In the fabrication of fibre-reinforced polymer composites investigated herein, woven glass fibre mats were used. These woven fibre reinforcement are created by a process of interweaving bundles of untwisted unidirectional glass filaments (yarns). The effective properties of resin-impregnated glass fibre yarns are determined in Unit Cell 2. When assembled according to designated weaving patterns and after bonding the glass fibre bundles with the polymer resin, individual fabric layers are stacked together to form a consolidated composite laminate. The effective properties of the composite laminate are evaluated in Unit Cell 3. In the hierarchical procedure/methodology described above, Unit Cell 3 utilizes input from Unit Cells 1 and 2 to facilitate the modelling of thermo-mechanical responses of fibre-reinforced polymer composites exposed at elevated temperature. 


\subsection{Description of the Multiple Length Scale Unit Cells}

\subsubsection{Configuration of Rhombic Dodecahedron-Shaped Unit Cell 1}

In Unit Cell 1, an ideal distribution (e.g., uniform dispersion and full matrix-suspension) of fire retardant additive particles is assumed. Fire retardant additives used in this work include an intumescent system (melamine phosphate) and whiskers of a cellulosic charring agent (Visil), both of which are idealized as micro-sized particulates. Since the dimensions of these particulate additives are larger than the gaps that exist between the individual fibres in a yarn, it is assumed that the additives are not embedded into the fibre bundles. It is therefore assumed herein that the fibres in the yarns are held together by an unmodified resin matrix while the spaces between yarns or fabric layers are filled by fireretarded resin matrix systems. The mechanical properties of Visil are assumed to be qualitatively similar to those of the control resin while those of melamine phosphate are considered to be negligible relative to the unmodified matrix. This assumption offers a great convenience by allowing Visil and melamine phosphate particles to be treated as if they were epoxy matrix and internal composite voids, respectively. The idealization of melamine phosphate particles as voids within the resin formulation delivers an important simplification; the composites fire-retarded by the intumescent additive can now be considered as a homogeneous and unmodified resin medium with void inclusions similar to those naturally resulting from manufacturing processes. In this study, it is noteworthy that the total void content of intumescent fire-retarded composite is the summed volume fractions of the intumescent and internal pores within the composite. There is no significant mass lose from fibre-reinforced polymer composites exposed within the working temperature range, ambient to $150^{\circ} \mathrm{C}$, in this study. As a consequence, mass loss due to resin matrix depolymerization has been ignored in our analysis.

The micromechanical idealization of the melamine phosphate fire retardant-modified resin system results in a $3 \mathrm{D}$ unit cell containing a significant void volume fraction. The shape of this $3 \mathrm{D}$ unit cell is dependent on the assumptions made about the spatial distribution of fire retardant particles within the resin matrix. While any such distribution would not be necessarily more realistic than others, there could be significant differences in the effective properties obtained from such unit cells, in particular when various degrees of anisotropy are considered. Statistically, due to the random dispersion of fire-retardant 
particles in the resin matrix, isotropy is expected at a macroscopic level. The spatial distributions of fire retardant additives is therefore one of the major considerations required in choosing the shape of the unit cell. Another important consideration is the topological complexity of the shape of the chosen unit cell. According to research findings in Ref. [24], a rhombic dodecahedron, (see Fig. 1(a)), offers a compromise by assuming a face centered cubic distribution of particulates within the resin matrix. While complete isotropy can never be realized in any regular packing pattern, face centered cubic packing arrangements result in configurations of reasonably weak anisotropy. In this study the characteristic topology of a rhombic dodecahedron is applied in Unit Cell 1 for the purposes of determining the effective properties of the resin matrix systems modified by fire retardant additives.

In this study, the shape of the voids is idealized as a single sphere of a defined volume, Fig. 1(b), and this is assumed to be close enough to reality when considering air bubbles or volatile pressureinduced internal composite pores. The inclusion of voids within the unit cell introduces an internal boundary which is not constrained in any fashion, thus can be treated as a free surface. However, the external boundary is subjected to some strict boundary conditions in order to reflect effects of periodic packing of the inclusions within the unit cell. A more detailed discussion of these boundary conditions including a systematic derivation is found in Ref. [24].

\subsubsection{Configuration of a Hexagonally-Shaped Unit Cell 2}

The interwoven pattern of yarns in a woven fabric introduces various degrees of waviness. The scale of undulations of yarns is usually much greater than that of fibre diameters and therefore yarns in woven fabric composites can be reasonably idealized as unidirectional fibre-reinforced composites. The effects of waviness are discussed later in Section 2.3.2. Microscopic analysis of the cross-section of a yarn revealed that the individual fibres are circular and have a fairly uniform diameter. However, the distribution of fibres in the plane of the cross-section is random. In order to simplify the problem investigated in this study, an idealized regular arrangement of fibres is assumed and is illustrated in Fig. 2. Again, depending on the assumed pattern of distribution of fibres in the cross-sectional plane, unit cells of varying shapes can result. To maintain the transverse isotropic behaviour possessed by unidirectional 
composites with randomly distributed fibres, a hexagonal packing arrangement is assumed [25]. The micromechanical analyses of such a yarn can then be simplified to a generalized plane strain problem in the plane of a cross-section of the yarn. Consequently, a hexagonal unit cell illustrated in Fig. 2 and referred to as Unit Cell 2 is adopted. A coordinate system is introduced to facilitate the analysis and is described as follows; axis 1 is aligned with the direction of fibres as conventionally adopted in composite analysis, and axes 2 and 3 are perpendicular to the longitudinal direction of the fibres; i.e., they lie in the cross-sectional plane of the yarn. In this paper, the 23 plane is designated the working plane for solving this two-dimensional generalized plane strain problem.

Unit Cell 2 as shown in Fig. 2 is bounded by the following three pairs of sides namely:

$$
x_{2}= \pm b, \quad x_{2}+\sqrt{3} x_{3}= \pm 2 b, \quad x_{2}-\sqrt{3} x_{3}= \pm 2 b
$$

where $b$ is half of the spacing between two neighboring fibres, as shown in Fig. 2. The fibre volume fraction of a yarn in a woven fabric can be calculated from the area of the unit cell and the fibre diameter. The unit cell is then analyzed as a generalized plane strain problem using FE to calculate the effective Young's moduli, the Poisson's ratios and shear moduli in the 23 plane. In order to perform this analysis, the displacement boundary conditions on the three paired sides are required;

$$
\begin{aligned}
& \left.\left(\left.u_{2}\right|_{x_{2}=b}-\left.u_{2}\right|_{x_{2}=-b}\right)\right|_{x_{3}}=2 b \varepsilon_{2}^{0},\left.\quad\left(\left.u_{3}\right|_{x_{2}=b}-\left.u_{3}\right|_{x_{2}=-b}\right)\right|_{x_{3}}=0, \\
& \left.\left(\left.u_{2}\right|_{x_{2}+\sqrt{3} x_{3}=2 b}-\left.u_{2}\right|_{x_{2}+\sqrt{3} x_{3}=-2 b}\right)\right|_{\sqrt{3} x_{2}-x_{3}}=b \varepsilon_{2}^{0}+\sqrt{3} b \gamma_{23}^{0}, \\
& \left.\left(\left.u_{3}\right|_{x_{2}+\sqrt{3} x_{3}=2 b}-\left.u_{3}\right|_{x_{2}+\sqrt{3} x_{3}=-2 b}\right)\right|_{\sqrt{3} x_{2}-x_{3}}=\sqrt{3} b \varepsilon_{3}^{0}, \\
& \left.\left(\left.u_{2}\right|_{x_{2}-\sqrt{3} x_{3}=2 b}-\left.u_{2}\right|_{x_{2}-\sqrt{3} x_{3}=-2 b}\right)\right|_{\sqrt{3} x_{2}+x_{3}}=b \varepsilon_{2}^{0}-\sqrt{3} b \gamma_{23}^{0}, \\
& \left.\left(\left.u_{3}\right|_{x_{2}-\sqrt{3} x_{3}=2 b}-\left.u_{3}\right|_{x_{2}-\sqrt{3} x_{3}=-2 b}\right)\right|_{\sqrt{3} x_{2}+x_{3}}=-\sqrt{3} b \varepsilon_{3}^{0},
\end{aligned}
$$

where notations $\left.\right|_{x_{2}=b}$ and $\left.\right|_{x_{2}=-b}$, etc., inside the parentheses indicate the sides while $\left.\right|_{x_{3}}$, etc., outside the parentheses indicate the common coordinates shared by the corresponding points on paired hexagonal sides. Taking the forth line of Eq. 2(a) as an example, the displacement, $u_{2}$, at point $\mathrm{A}$ on side $x_{2}+\sqrt{3} x_{3}=2 b$ and at point $\mathrm{B}$ on side $x_{2}+\sqrt{3} x_{3}=-2 b$ are related to the macroscopic/average strains $\varepsilon_{2}^{0}$ 
and $\gamma_{23}^{0}$ where points $\mathrm{A}$ and $\mathrm{B}$ share the same value of $\sqrt{3} x_{2}-x_{3}$ as illustrated in Fig. 2. In performing FE mesh, it was ensured that the nodes on paired sides were appropriately located as points A and B. The boundary conditions represented by Eq. (2a) were then imposed onto such corresponding nodes on the paired sides. Due to the nature of the generalized plane strain problem as described in Ref. [26], a longitudinal macroscopic strain, $\varepsilon_{1}^{0}$, is also allowed. This macroscopic strain is treated as a single independent degree of freedom for the whole unit cell despite the fact that it does not appear in Eq. (2a). The implementation in ABAQUS is through a longitudinal degree of freedom at the reference node for the whole mesh as described in Ref. [27].

To calculate the effective shear moduli, $G_{12}^{0}$ and $G_{13}^{0}$, an anticlastic problem has to be solved under the displacement boundary conditions imposed on relevant sides of the hexagon:

$$
\begin{aligned}
& \left.\left(\left.u_{1}\right|_{x_{2}=b}-\left.u_{1}\right|_{x_{2}=-b}\right)\right|_{x_{3}}=2 b \gamma_{12}^{0}, \\
& \left.\left(\left.u_{1}\right|_{x_{2}+\sqrt{3} x_{3}=2 b}-\left.u_{1}\right|_{x_{2}+\sqrt{3} x_{3}=-2 b}\right)\right|_{\sqrt{3} x_{2}-x_{3}}=b \gamma_{12}^{0}+\sqrt{3} b \gamma_{13}^{0}, \\
& \left.\left(\left.u_{1}\right|_{x_{2}-\sqrt{3} x_{3}=2 b}-\left.u_{1}\right|_{x_{2}-\sqrt{3} x_{3}=-2 b}\right)\right|_{\sqrt{3} x_{2}+x_{3}}=b \gamma_{12}^{0}-\sqrt{3} b \gamma_{13}^{0} .
\end{aligned}
$$

In the absence of an appropriate type of element for this anticlastic problem in ABAQUS, an analogy to the steady state heat transfer problem can be resorted as both problems are governed by the same Laplace equation. Consequently, the heat transfer elements in ABAQUS can be used with the same meshes generated for the analysis in the ABAQUS generalized plane-strain problem. Displacement $u_{1}$ will be interpreted as temperature for the heat transfer problem as described in Refs. [28, 29].

\subsubsection{Configuration of a Cuboid-Shaped Unit Cell 3}

In real applications of composite materials, there are usually a significant number of layers of woven fabric stacked together in order to achieve the desirable thickness. For the sake of simplicity and yet without losing generality, the woven fabric in this study is assumed to be in form of a plain weave in which the warp and fill yarns running in perpendicular directions interchange their positions in the $z$ direction. This regular woven pattern justifies the use of a unit cell to represent a composite layer. A composite laminate can then be considered as an assembly of such homogenized layers to form a 
structure such as the one schematically depicted as Unit Cell 3 in Fig. 3. Unit Cell 3 is cuboid-shaped and it contains both the matrix and woven yarns (warp and fill), each of which run over one full period of undulation. The three paired faces of this unit cell are given in Eq. $3[24,30]$ :

$$
x= \pm a, \quad y= \pm b, \quad z= \pm c,
$$

where $a, b$ and $c$ are the dimensions of the unit cell as depicted in Fig. 4. The volume of this cuboidshaped unit cell is calculated to be $8 a b c$. The displacement boundary conditions on the three paired faces excluding the edges are given [24]:

$$
\begin{array}{ll}
\left.\left(\left.u\right|_{x=a}-\left.u\right|_{x=-a}\right)\right|_{y, z}=2 a \varepsilon_{x}^{0}, & \left.\left(\left.v\right|_{x=a}-\left.v\right|_{x=-a}\right)\right|_{y, z}=0, \\
\left.\left(\left.w\right|_{x=a}-\left.w\right|_{x=-a}\right)\right|_{y, z}=0 ; & \text { between faces } x= \pm a \\
\left.\left(\left.u\right|_{y=b}-\left.u\right|_{y=-b}\right)\right|_{x, z}=2 b \gamma_{x y}^{0}, & \left.\left(\left.v\right|_{y=b}-\left.v\right|_{y=-b}\right)\right|_{x, z}=2 b \varepsilon_{y}^{0}, \\
\left.\left(\left.w\right|_{y=b}-\left.w\right|_{y=-b}\right)\right|_{x, z}=0 ; & \text { between faces } y= \pm b \\
\left.\left(\left.u\right|_{z=c}-\left.u\right|_{z=-c}\right)\right|_{x, y}=2 c \gamma_{x z}^{0}, & \left.\left(\left.v\right|_{z=c}-\left.v\right|_{z=-c}\right)\right|_{x, y}=2 c \gamma_{y z}^{0}, \\
\left.\left(\left.w\right|_{z=c}-\left.w\right|_{z=-c}\right)\right|_{x, y}=2 c \varepsilon_{z}^{0} & \text { between faces } z= \pm c
\end{array}
$$

where notations $\left.\right|_{x=a}$ and $\left.\right|_{x=-a}$, etc., inside the parentheses indicate the faces while $\left.\right|_{y, z}$, etc., outside the parentheses indicate the common coordinates shared by the corresponding points on the paired faces. The unit cell as presented here applies to other woven patterns, such as twill and harness satin, as far as the required boundary conditions are concerned. The only difference will be in the internal construction where yarns may undulate in a slightly different manner.

\subsection{Application of Loads and Effective Material Properties}

The macroscopic/average stresses $\sigma_{x}^{0}, \sigma_{y}^{0}, \sigma_{z}^{0}, \sigma_{x y}^{0}, \sigma_{y z}^{0}$ and $\sigma_{x z}^{0}$ are treated as key/extra degrees of freedom $[22,24,25]$ to the unit cell concerned after incorporating equation-based boundary conditions in FE analyses. These macroscopic stresses are assigned node numbers just like ordinary nodes. However, each of these nodes possesses a single degree freedom. The concentrated 'forces', $F_{x}, F_{y}, F_{z}, F_{x y}, F_{y z}$ and $F_{x z}$, are related to the macroscopic/average stresses by: 


$$
\sigma_{x}^{0}=F_{x} / V, \quad \sigma_{y}^{0}=F_{y} / V, \quad \sigma_{z}^{0}=F_{z} / V, \tau_{y z}^{0}=F_{y z} / V, \tau_{z x}^{0}=F_{z x} / V, \tau_{x y}^{0}=F_{x y} / V,
$$

where $V$ is the volume of the unit cell. In the case of Unit Cell 2, the volume, $V$, is replaced by the area, $A$, of the unit cell since the unit length is assumed in the third dimension and coordinates $x, y$, and $z$ are replaced by 1,2 , and 3 , respectively.

Given the macroscopic orthotropic nature of composite materials, typical effective material properties as represented by the unit cell under consideration are determined as follows [24, 25]:

$$
\begin{aligned}
& E_{x}^{0}=\sigma_{x}^{0} / \varepsilon_{x}^{0}=F_{x} / V \varepsilon_{x}^{0}, v_{x y}^{0}=-\varepsilon_{y}^{0} / \varepsilon_{x}^{0} \text { and } v_{x z}^{0}=-\varepsilon_{z}^{0} / \varepsilon_{x}^{0}, \text { for } F_{y}=F_{z}=F_{y z}=F_{z x}=F_{x y}=\Delta T=0 \\
& G_{y z}^{0}=\tau_{y z}^{0} / \gamma_{y z}^{0}=F_{y z} / V \gamma_{y z}^{0}, \text { for } F_{x}=F_{y}=F_{z}=F_{z x}=F_{x y}=\Delta T=0 \\
& \alpha_{x}^{0}=\varepsilon_{x}^{0} / \Delta T, \text { for } F_{x}=F_{y}=F_{z}=F_{y z}=F_{z x}=F_{x y}=0
\end{aligned}
$$

where $\alpha$ stands for thermal expansion coefficients and $\Delta T$ is the change in temperature. In order to evaluate for the thermal expansion coefficients, thermal loading in terms of a uniform temperature change, $\Delta T$, has to be applied. This is easily achieved in ABAQUS by using the "TEMPERATURE" option. The macroscopic/average strains are obtained from FE analysis, as required for evaluating the effective material properties. In the FE analysis, the actual magnitude of loads, including the 'forces' $F_{x}$, $F_{y}, F_{z}, F_{x y}, F_{y z}$ and $F_{x z}$ and the temperature change $\Delta T$ would not affect the value of effective properties evaluated, as long as the system behaves linearly.

\subsection{Finite Element Applications: Meshing and Material Properties}

\subsubsection{Finite Element Meshes}

For all unit cells, commercial FE codes PATRAN (MSC, 2005; MSC Software Corp., Los Angeles, CA) and ABAQUS 6.6-1 have been used for mesh generation and analysis, respectively. Meshes at different levels of refinement have been generated and were analyzed to confirm the convergence of these meshes; i.e., element sizes beyond which further refinement would not result in any substantial improvement in the accuracy of the results. The equations describing the boundary conditions for all unit cells were implemented using the "EQUATION" option in ABAQUS [27]. Care was taken to avoid the disruption of the node pairing systems by sorting numbers in paired node sets in accordance 
with the relevant translational symmetries. A short FORTRAN (The Fortran Company, Tucson, AZ) code sufficed in achieving this objective.

The mesh generated using a matrix containing 20 vol. \% voids (Unit Cell 1) is shown in Fig. 1 and was briefly discussed above. This rhombic dodecahedral-shaped unit cell can be considered as an assembly of four identical hexahedra, including the volume occupied by the void. The partitioning scheme described in Ref. [24] has been adopted in this work in order to avoid distortion of elements in the mesh. Twenty-node 3D brick elements were used to generate the meshes for the matrix. The total void volume in the unit cell representing the matrix is constituted of the volume spaces occupied by air bubbles, volatiles and/or the intumescent particles. The solid part of unit cell is assumed to be the unmodified resin matrix material exhibiting linear elastic and isotropic characteristics. This is also true for polymer composites containing Visil since the mechanical properties of the later are assumed to be the same as those of the unmodified resin matrix.

In Unit Cell 2, it is assumed that fibres have a circular cross-sectional area and that perfect interfacial bonding exists between the fibres and the resin matrix. As already mentioned above, the portion of the matrix embedded in the yarns does not contain fire retardants (melamine phosphate or Visil) as these additives are too big to enter into the spaces between the fibre filaments. However, despite the absence of particulate material in the matrix within the yarn, voids could potentially be present in form of trapped air bubbles and/or volatiles generated during curing as well as during laminate exposure at elevated temperatures. Thus, in general, it is necessary that the resin used in Unit Cell 2 be modified to reflect inclusions and effects of the voids. In this study, both the fibre and the modified resin matrix have been assumed to be independently homogeneous and isotropic. An example of a mesh generated for the hexagonal-shaped Unit Cell 2 at a fibre volume fraction of $60 \%$ is shown in Fig. 2. Eight-node quadrilateral elements were used in the generation of the fibre and matrix meshes.

For Unit Cell 3, the bonding between yarns and resin is assumed to be perfect. Using the dimensions of the unit cell obtained from scanning electron microscope (SEM) analyses $(a=3.05, b=$ 3.05 and $c=0.19 \mathrm{~mm})$, the volume of the unit cell was calculated to be $14.14 \mathrm{~mm}^{3}$. 
In this study it is assumed that the axes of warp and fill yarns are described by the following cosine functions:

$$
\pm \frac{h}{2} \cos (\pi x / a) \quad \text { and } \quad \pm \frac{h}{2} \cos (\pi y / b)
$$

where $h$ is the thickness of the cross-section of a yarn as shown in Fig. 5. The cross-section of the yarns is assumed to be defined by the same functions above but truncated at both ends as determined by the dimension $w$ (see Fig. 5). For the woven fabric used herein, it is assumed that $w=2.38 \mathrm{~mm}$ and $h=0.16$ $\mathrm{mm}$ while the spacing between two neighboring warp yarns or fill yarns is $g_{x}$ or $g_{y}=0.67 \mathrm{~mm}$. The parameters $w, h, g_{x}$ and $g_{y}$ are indicated in Fig. 5 and were all obtained from SEM analyses. The $z$ axis is in the thickness direction of the woven fabric polymer composite. The average cross-sectional area of each yarn is calculated using equation (8) to obtain a value of $0.29 \mathrm{~mm}^{2}$ :

$$
A_{y a r n}=2 \int_{-w / 2}^{w / 2} \frac{h}{2} \cos (\pi x / a) d x \quad w \leq a
$$

The average arc length of each yarn axis was calculated to be $6.11 \mathrm{~mm}$ from:

$$
S_{y a r n}=\int_{-a}^{a} \sqrt{1+\frac{\pi^{2} h^{2}}{4 a^{2}} \sin ^{2}(\pi x / a) d x}
$$

The above is an incomplete elliptic integral of the second kind which can be evaluated using any mathematical software or handbook. Each unit cell contains two complete and four half yarns where the volume fraction of the woven yarns is calculated as 0.51 using:

$$
4 A_{\text {yarn }} S_{\text {yarn }} / V
$$

The mesh patterns for Unit Cell 3 are shown in Fig. 3 where twenty-node 3D brick elements (hexahedron) have been used to generate the meshes for the regular part of the matrix and the yarns. For the matrix filling the square gaps between yarns, ten-node 3D tetrahedron elements were used to fit the complicated uneven surface left behind by the interlacing yarns. Compatibility between laminate regions meshed using tetrahedron elements and those meshed with hexahedron elements was achieved by using fifteen-node 3D wedge elements within the transition region as shown in Fig. 6. A complete mesh of Unit Cell 3 contains a total of 11,744 elements (i.e., 5,600 brick-, 5,184 wedge- and 960 tetrahedron-type) and 42,285 nodes. 


\subsubsection{Coordinate Transformation}

Materials properties of the yarns as represented by Unit Cell 2 are of the transversely isotropic nature with an elastic behaviour that is wholly defined using five independent effective material properties; $E_{1}^{0}, E_{2}^{0}=E_{3}^{0}, v_{12}^{0}=v_{13}^{0}, v_{23}^{0}$ and $G_{12}^{0}=G_{13}^{0}$, as given in the materials' principal axes. It should be noted that the term, $G_{23}^{0}=E_{2}^{0} /\left[2\left(1+v_{23}^{0}\right)\right]$, is not an independent parameter. These material properties are input parameters that are required to perform FE analysis in Unit Cell 3. As a result of the undulations in fill and warp yarns, the materials' principal axes vary along the axes of yarns within Unit Cell 3. To formulate the FE model in Unit Cell 3 for the material representing the yarns, coordination transformations have to be made from the materials' principal axes 123 to the global axes $x y z$. The orientation of the principal axes of the material vary from point to point, hence the coordinate transformation matrix has to be defined similarly. This condition is achieved in ABAQUS [27] by utilizing a user-defined orientation subroutine, “ORIENT", in which the coordinate transformation matrix can be defined according to the spatial location of the point of interest. In the "ORIENT" subroutine, the user has to define a $3 \times 3$ coordinate transformation matrix $[T]$ whose values are directional cosines of the local coordinate axes (i.e. the materials' principal axes). $T_{11}, T_{21}$ and $T_{31}$ form a unit vector which defines the direction of material axis $1 ; T_{12}, T_{22}$ and $T_{32}$ and $T_{13}, T_{23}$ and $T_{33}$ define axes 2 and 3 , respectively.

The yarns in the $x$ direction (warp) of the Unit Cell 3 are of two different patterns (differing by a phase of half a period and hence sharing the same function but in the opposite manner). For the two half yarns on the sides of the unit cell, the axis is given by the term $-0.5 h \cos (\pi x / a)$, for which a tangent is further determined by differentiating the function with respect to $x$. The direction cosines of the tangent as the elements of the $[T]$ matrix can be expressed as follows:

$$
T_{11}=1 / \sqrt{1+\frac{\pi^{2} h^{2}}{4 a^{2}} \sin ^{2}(\pi x / a)}, T_{21}=0, T_{31}=\frac{\pi h}{2 a} \sin (\pi x / a) / \sqrt{1+\frac{\pi^{2} h^{2}}{4 a^{2}} \sin ^{2}(\pi x / a)}
$$

The materials' principal axis 2 always lies parallel to the $y$ axis hence;

$$
T_{12}=0, T_{22}=1, T_{32}=0 \text {. }
$$

As axis 3 must be perpendicular to axes 1 and 2, the direction cosines between axis 3 and $z$ axis are:

$$
T_{13}=-T_{31}, T_{23}=0, T_{33}=T_{11} \text {. }
$$


For the whole warp yarn along the $x$ direction in the middle of the unit cell, the axis is given by the term $0.5 h \cos (\pi x / a)$. The coordinate transformation matrix $[T]$ can be obtained in a similar fashion:

$$
\begin{array}{ll}
T_{11}=1 / \sqrt{1+\frac{\pi^{2} h^{2}}{4 a^{2}} \sin ^{2}(\pi x / a)}, T_{21}=0, T_{31}=-\frac{\pi h}{2 a} \sin (\pi x / a) / \sqrt{1+\frac{\pi^{2} h^{2}}{4 a^{2}} \sin ^{2}(\pi x / a)} ; \\
T_{12}=0, T_{22}=1, T_{32}=0 ; & T_{13}=-T_{31}, T_{23}=0, T_{33}=T_{11} .
\end{array}
$$

The same applies to the fill yarns in the $y$ direction. For the two half yarns on the sides, the axis is given by $0.5 h \cos (\pi y / b)$ to obtain:

$$
\begin{aligned}
& T_{11}=0, T_{21}=1 / \sqrt{1+\frac{\pi^{2} h^{2}}{4 b^{2}} \sin ^{2}(\pi y / b)}, T_{31}=-\frac{\pi h}{2 b} \sin (\pi y / b) / \sqrt{1+\frac{\pi^{2} h^{2}}{4 b^{2}} \sin ^{2}(\pi y / b)} ; \\
& T_{12}=-1, T_{22}=0, T_{32}=0 ;
\end{aligned}
$$

For the whole fill yarn along the $y$ direction in the middle of the unit cell, the axis is described by $-0.5 h \cos (\pi y / b)$ to obtain:

$$
\begin{array}{lc}
T_{11}=0, T_{21}=1 / \sqrt{1+\frac{\pi^{2} h^{2}}{4 b^{2}} \sin ^{2}(\pi y / b)}, T_{31}=\frac{\pi h}{2 b} \sin (\pi y / b) / \sqrt{1+\frac{\pi^{2} h^{2}}{4 b^{2}} \sin ^{2}(\pi y / b)} ; \\
T_{12}=-1, T_{22}=0, T_{32}=0 ; & T_{13}=0, T_{23}=-T_{31}, T_{33}=T_{21} .
\end{array}
$$

The $[T]$ matrix as obtained above provides ABAQUS with sufficient information to transform materials' stiffness matrices for the yarns from the materials' principal axes 123 to the global axes $x y z$, without further interference from the user.

\section{$3 \quad$ Experimental Methodology for Model Validation}

\subsection{Materials}

A low-viscosity and room temperature-curing base epoxy resin containing 1,4-butanediol diglycidylether (Young's modulus $=3.2 \mathrm{GPa}$; Poisson's ratio $=0.38$; Araldite LY5052), and a hardener based on modified cycloaliphatic amines (HY5052) (Huntsman, Inc.); woven roving E-glass (300 g/ $\left.\mathrm{m}^{2}\right)$ (Young's modulus $=72 \mathrm{GPa}$; Poisson's ratio $=0.22$; Glasplies, UK); Visil, a cellulosic fibre containing polysilicic acid, in pulverized form (from initial length $40 \mathrm{~mm}, 3.5$ dtex and diameter $17 \mu \mathrm{m}$ ) (Sateri Fibres, Finland); an intumescent (Antiblaze NH) containing melamine phosphate (Rhodia Specialities 
Ltd., now Albemarle) and K-type thermocouples of diameter $0.3 \mathrm{~mm}$ (Omega Engineering Inc., UK) were used in this study.

\subsection{Preparation of Composite Laminates}

Glass fibre-reinforced epoxy laminates with/without fire retardant additives were used to validate the numerical model. The laminates were fabricated from plain woven E-glass fabric $\left(300 \mathrm{~g} / \mathrm{m}^{2}\right)$ and epoxy resin, LY5052. Eight ply glass fibre-reinforced epoxy composites with/without fire retardant additives were fabricated via a wet lay-up method [31,32]. The impregnated woven roving E-glass fabric layers were stacked, vacuum bagged and then cured at elevated temperature conditions $\left(80^{\circ} \mathrm{C} ; 8 \mathrm{~h}\right)$ under an applied pressure of 1 bar. The laminates had a fibre weight fraction of 50\% corresponding to a volume fraction of $\sim 29 \%$. Three samples were fabricated; 1) a control sample containing 28.65 and 71.35 vol.\% glass fibre and epoxy resin, respectively (EP); 2) a fire-retarded composite containing 50\% w/w glass fibre $(28.65 \%$ vol.), $42.5 \% \mathrm{w} / \mathrm{w}$ resin $(60.65 \%$ vol. $), 3.75 \% \mathrm{w} / \mathrm{w}$ Visil $(5.35 \%$ vol.) and $3.75 \% \mathrm{w} / \mathrm{w}$ melamine phosphate $(5.35 \%$ vol.), respectively; otherwise $15 \% \mathrm{w} / \mathrm{w}$ fire retardant additives with respect to resin weight (EP-15); and 3) another fire-retarded composite containing glass fibre 50\% w/w $(28.65 \%$ vol.), $40 \% \mathrm{w} / \mathrm{w}$ resin (57.07\% vol.), $2.5 \% \mathrm{w} / \mathrm{w}$ Visil (3.57\% vol.) and melamine phosphate $7.5 \% \mathrm{w} / \mathrm{w}$ ( $10.71 \%$ vol.), respectively; otherwise $20 \% \mathrm{w} / \mathrm{w}$ fire retardant additives with respect to resin weight (EP20). For detailed resin formulation, composition and other physical (density, thermal stability, and thermal properties) data, the reader is referred to our previous publication [31].

\subsection{Flexural Property Measurements}

The flexural moduli of glass fibre-reinforced specimens $(120 \mathrm{~mm} \times 15 \mathrm{~mm} \times$ nominal thickness $\sim 3.0 \mathrm{~mm}$ ) were measured in three-point bending mode using a $100 \mathrm{~N}$ load cell Instron 3369 tensometer with a load and displacement control. The load was applied at a cross-head speed of $1 \mathrm{~mm} / \mathrm{min}$. The flexural modulus, E, was calculated using the Engineers' bending theory as described in our preceding paper [31]. The maximum allowable displacement at the loading point was restricted to $3 \mathrm{~mm}$ in order that the specimens recovered completely to be re-used for elevated temperature experiments; e.g., 
specimen deformation was restricted to the elastic region. A couple of virgin specimens for each sample were repeatedly loaded and unloaded (three cycles) within the $3 \mathrm{~mm}$ displacement threshold and it was found that they completely recovered their original stiffness at the conclusion of the cyclic test. This procedure was designed so that baseline flexural properties for each specimen could be determined against which elevated temperature properties of that particular specimen could then be directly compared.

The effect of convective heat on the mechanical properties of fibre-reinforced polymer composites with/without fire retardant additives was observed by heating the specimens from ambient temperature to desired temperatures $\left(50,75,100,125\right.$ and $\left.150^{\circ} \mathrm{C}\right)$ at a heating rate of $10^{\circ} \mathrm{C} / \mathrm{min}$ inside a resistance-controlled and fan-assisted chamber. In each experiment, upon reaching the desired temperature and allowing for equilibration $(120 \mathrm{~s})$, the flexural modulus of the specimen was determined in-situ; e.g., at the elevated temperature. Detailed information about the experimental procedure has been published in our preceding papers $[31,32]$.

\section{$4 \quad$ Results and Discussion}

\subsection{Thermo-Mechanical Performance of Epoxy at Elevated Temperature}

Despite the fact that the epoxy polymer used in this study does not show a significant mass loss at temperatures below $350^{\circ} \mathrm{C}$, it however, softens and loses its stiffness at elevated temperature. Fig. 7a shows the variation of the flexural modulus of the unmodified epoxy resin as a function of temperature. Initially, the flexural modulus gradually decrease followed by a stage where its rate of loss (i.e., softening) is highest and this happens as one approaches the glass transition temperature, $T_{\mathrm{g}}$. The glass transition temperatures of both unmodified and fire-retarded epoxy resin systems used in this study were found to be $\sim 130^{\circ} \mathrm{C}[31]$. The flexural modulus values measured at temperatures above the $T_{\mathrm{g}}$ are negligible, Fig. 7a. In our previous work [31], it was shown that data patterns similar to that presented in Fig. 7(a) can be accurately described by a tanh function, Eq. (13):

$$
E_{T}=\frac{E_{0}+E_{T, 150}}{2}-\left[\frac{E_{0}+E_{T, 150}}{2}\right] \tanh \left(k\left(T-T_{50 \%}\right)\right.
$$


where $E_{T}$ is the flexural modulus at temperature $T, E_{0}$ is the room temperature flexural modulus, $E_{T, 150}$ is the flexural modulus at $150^{\circ} \mathrm{C}, k$ a curve-fitting function that describes the breath of the propertytemperature curve, and $T_{50 \%}$ the temperature at which $50 \%$ of the room temperature stiffness is lost. A curve calculated using Eq. (13) is also shown as a solid line in Fig. 7(a) together with the fitting parameters. It should be noted, however, that the tanh function was derived from phenomenological (curve fitting) observations hence the fitted parameters do not represent in any way the actual microscopic/physical aspects of the thermal softening processes. Due to the significant loss in stiffness observed when polymer composites are exposed at temperature close to the $T_{\mathrm{g}}$, it is therefore of little significance to consider the mechanical behaviour of laminate composites at temperatures well above the glass transition temperature. Thus, in this work, micromechanical FE analyses have been limited to temperatures up to $150^{\circ} \mathrm{C}$.

The normalised flexural moduli as a function temperature were calculated for fibre-reinforced epoxy composites with/without fire retardants and are shown in Fig. 7(b). The elevated temperature flexural moduli of these composites were normalized with respective to corresponding room temperature values which are 13.8, 13.1 and 11.7 GPa for EP/F, EP/F-15 and EP/F-20, respectively. The normalised flexural modulus of all the composites gradually decreases at temperatures as low as $50^{\circ} \mathrm{C}$ with a rapid acceleration in the flexural stiffness happening between 100 and $120^{\circ} \mathrm{C}$ due to the softening of the matrix. At $150^{\circ} \mathrm{C}$, the flexural modulus of all FRP composites studied herein is on average $37 \%$ of the room temperature measured values. The experimental data in Fig. 7(b) is fitted to a tanh function analogous to the one in Eq. (13). These data suggest that there is no significant difference in the thermomechanical response of composites with/without fire retardants at temperatures below $150^{\circ} \mathrm{C}$.

\subsection{Material Property Variation and Sensitivity Studies}

The material properties of composite laminate constituent materials are critical input variables that are required in order to theoretically estimate effective properties of composites using micromechanical analysis. Some of the material properties of constituent elements at elevated temperatures were not readily available to the user and in such cases assumptions were made about the 
property-temperature relationship. One such case is that of the Poisson's ratio of glass fibres used as reinforcement. In the case that an input parameter has been assumed, there are consequences if the assumed property-temperature relationship deviates from the actual dependency. From a micromechanical viewpoint, variations in the calculated material properties are due to changes in the properties of the constituent materials of the composite. However, variations in some of the constituent properties may not have as much effects on the overall composite behaviour as others. In order to evaluate the sensitivity of estimated material properties on the accuracy of the models, a parametric study was undertaken. Parametric studies are useful in revealing the sensitivity of effective composite properties to those of its constituents.

Due to the thermal inertness of the glass fibres within the temperature range of interest (ambient $150^{\circ} \mathrm{C}$ ), its Young's modulus is assumed not to be significantly affected and is therefore kept constant [33]. The changes in the effective properties of the composite laminates are therefore associated to variations in the Poisson's ratio of fibre together with the Young's modulus and Poisson's ratio of the epoxy resin matrix. In undertaking this parametric study, the Poisson's ratios of fibre and resin as well as the Young's modulus of matrix have been considered. The effect of Poisson's ratio of glass fibres on the effective material properties of the composite was investigated at set values of $0.1,0.22$ and 0.3 . Results from the parametric study revealed that the effective material properties of the composite are not sensitive to the Poisson's ratio of the glass fibre. The implication of this observation is that, in the absence of an accurately measured value, any reasonable guess for a Poisson's value between 0.1 and 0.3 would suffice at both ambient and elevated temperature conditions.

The effective mechanical properties of the composite were investigated for different combinations of constituent material properties wherein the Young's modulus of the epoxy resin was perturbed between 1 and $5 \mathrm{GPa}$ with the fibre and matrix Poisson's ratios set at 0.22 and 0.38 , respectively. Increasing the Young's modulus of the resin matrix effectively has the same effect on the composite Young's and shear moduli as well as the in-plane Poisson's ratio. Thus, the material properties of the composites are sensitive to the Young's modulus of the epoxy resin. In another set of parametric studies, the Poisson's ratio of the matrix was perturbed between 0.28 and 0.48 while holding its Young's modulus 
value at 3.2 GPa. The effective material properties of the composites including the Young's moduli and Poisson's ratio increased with the increase in the Poisson's ratio of the matrix. The effective shear modulus of the composite was however, slightly reduced with increases in the Poisson's ratio of the matrix. These observations reveal the sensitivity of the composite material properties to variation in the Poisson's ratio of the matrix. These parametric outcomes point to the necessity of incorporating accurate property-temperature dependencies for the matrix's Young's modulus and Poisson's ratio in the simulation in an attempt to predict the effective properties of the composites at elevated temperatures.

\subsection{Model Validation against Experimental Data}

In order to validate the micromechanical FE model, theoretical predictions of the effective composite properties have been validated against experimental data where such data was measured. Due to the restrictive loading mechanisms for composites exposed at elevated temperature, only flexural bending (three-point bending mode) tests were performed for numerical model validation purposes in this study. By using a literature glass fibre density value of $2.54 \mathrm{~kg} / \mathrm{m}^{3}$ and experimentally measured composite densities $\left(\sim 1.02 \mathrm{~kg} / \mathrm{m}^{3}\right)$ for the unmodified and modified resin [31] and assuming the density of constrained Visil and melamine particles to be the same as that of the cured resin, the fibre volume fraction was calculated to be approximately $29 \%$ for all three different composites. For the validation of the numerical model, experimentally obtained flexural moduli data for the resin matrix only at selected temperatures was used as input data in Unit Cell 1. The Young's moduli and Poisson's ratios of resin systems containing 'artificial' voids due to the presence of melamine phosphate were calculated and are used in Unit Cell 3 for fire-retarded FRP composites. As a first approximation and in absence of experimental data, the Poisson's ratio of the resin matrix was assumed to be constant at 0.38 for temperatures up to $150^{\circ} \mathrm{C}$. The glass fibre properties including the Young's modulus and Poisson's ratio were also assumed to remain unchanged over the same temperature range. With these assumptions in place, the effective behaviors of the woven fabric reinforced composite with/without fire retardants were determined from micromechanical FE analyses. 
The micromechanical model developed in this study can predict the effective flexural modulus of composites with/without fire retardants at temperatures between 25 and $150^{\circ} \mathrm{C}$. The accuracy of this micromechanical model is shown in Fig. 8, wherein the experimentally measured and theoretically predicted are plotted against each other. All but three data points in Fig. 8 are in close proximity to the line $x=y$ indicating that the micromechanical model developed herein is sufficient in estimating the flexural stiffness degradation of fibre-reinforced epoxy composite with/without fire retardants. Following the validation of the micromechanical model and satisfaction with the model's level of accuracy other material properties of the fibre-reinforced composites were predicted. The predicted variation with temperature of effective composite properties (elastic modulus, Poisson's ratio and shear modulus) is shown in Fig. 9.

The elastic moduli in the through-thickness (transverse) direction of fibre-reinforced composites with/without fire retardants were predicted as a function of temperature using the validated micromechanical model. The predicted elastic moduli values at elevated temperature were normalised by dividing by the room temperature-measured value and are plotted as a function of temperature in Fig. 9(a). The elastic moduli for all composite studied herein monotonically decrease with increasing temperature reaching negligible values at $150^{\circ} \mathrm{C}$. The rate of degradation of the through-thickness stiffness is fastest for EP/F-20 and slowest for EP/F. It is therefore, evident from these results that the incremental addition of fire retardants may have detrimental effects on the stiffness retention of resultant composites when exposed at elevated temperatures. At elevated temperatures, the interfacial bond strength between the resin and fire retardant particles may degrade leading to reduced stress transfer efficiency within the composite matrix. The discontinuity within the resin matrix would therefore be more profound in EP/F-20 than in EP/F or EP/F-15 hence the transverse elastic modulus-temperature trends shown in Fig. 9(a).

The in-plane, $v_{x y}^{0}$, and transverse, $v_{x z}^{0}=v_{y z}^{0}$, Poisson's ratios for the composites with/without fire retardants were predicted and are shown in Fig. 9(b) as a function of temperature. There are no significant differences in the predicted Poisson's ratio for all three composites. The in-plane Poisson's ratio gradually decrease between 25 and $130^{\circ} \mathrm{C}$ followed by a steep rise at temperatures above $130^{\circ} \mathrm{C}$. On 
the other hand, the transverse Poisson's ratios gradually increase with temperature up until $130^{\circ} \mathrm{C}$ after which the values slightly fall. The inflection points in both the in-plane- and transverse-temperature relationships may be associated with excessively enhanced undulations in the fill yarns coupled with the straightening of the warp yarns caused by the rapid degradation in the stiffness of the matrix at temperatures around the glass transition temperatures of the matrix. The normalized in-plane and transverse shear moduli of the composites with/without fire retardant additives were predicted using the micromechanical FE model developed in this study and these data are shown in Fig. 9(c). The trends observed in the shear modulus-temperature relationship are similar to those observed for the transverse elastic modulus in Fig. 9(a). The normalized in-plane and transverse shear moduli decline in a linear fashion with temperature for EP/F and EP/F-15. The normalized shear moduli-temperature dependency for EP/F-20 shows a gradual initial decrease followed by a rapid degradation in the shear moduli between 50 and $100^{\circ} \mathrm{C}$. There is no significant difference between the in-plane and transverse shear behaviors when a composite is tested in these two modes. Fire-retarded composites show a more rapid depletion in shear modulus with temperature when compared to fibre-reinforced composites with an unmodified resin matrix. The loss of resin/fire retardant particle interfacial strength as the temperature increase may be the cause for the accelerated degradation in the shear moduli of fire-retarded composites relative to their unmodified counterparts; e.g., control composite laminates.

Despite the limited volume of experimentally determined mechanical properties of composite at elevated temperatures, the micromechanical FE model developed in this study was satisfactorily validated. Reasonable correlation between the experimentally measured and theoretically predicted flexural moduli at elevated temperature for composites with/without fire retardants were observed (see Fig. 8). Other mechanical property-temperature relationships were then predicted using this validate numerical model. The complexity of acquiring some mechanical property data such as the transverse elastic and shear moduli at elevated gives the impetus for researchers to develop numerical model that can accurately predict these behaviors. In the design of engineering composite structures that are prone to fire, it is imperative that designers understand the structural response of those structures when exposed to high temperatures. Numerical simulation of thermo-mechanical response of engineering composites is 
not only cost-effective but it provides rapid screening for new or existing composite materials for applications in fire prone environments. The results presented in this work serve as a first attempt by the authors in establishing a practical methodology in the fire structural behaviour of polymer composite materials and will help build up confidence on the predictive tools in this area of research. The ultimate objective is to offer tools to engineering composite designers at materials design level and also provide effective properties of such composites for analyses of structures made of such materials during the processes of design optimization of engineering structures.

\section{Conclusions}

Three unit cells have been used at their inherent length-scales for micromechanical FE analyses of fire retardant woven fabric composites exposed at elevated temperatures. In the first unit cell, Unit Cell 1, material properties of the resin matrix were adjusted to take into account the effect of particulate additives and voids (i.e.; trapped air bubbles and volatiles) on the mechanical performance of the fibrereinforced composites at elevated temperatures. The effective properties of yarns were predicted in their material's principal axes using Unit Cell 2. The outcomes from Unit Cell 1 and 2 were then incorporated into Unit Cell 3 for the prediction of effective properties of woven fabric composites with/without fire retardant additives. In order to investigate the sensitivity of micromechanical FE model developed herein, parametric variations on essential input material properties were conducted. The micromechanical FE model developed in this study was then satisfactorily validated against experimental measured flexural modulus data. Other effective properties of composites at elevated temperatures which would otherwise be difficult to experimentally measure were then predicted using this FE model. The theoretically predicted results determined for composite with/without fire retardants at elevated temperatures follow expected trends; e.g., the mechanical properties decrease with increase in the exposure temperature. The micromechanical FE analyses has potential for application in the assessment of the fire structural behaviour of engineering composites simultaneously subjected to mechanical loads and fire impingement. 


\section{Acknowledgments}

This research was performed as part of a large collaborative project between The University of Manchester's Fire Engineering Research group and the University of Bolton's Fire Materials group on 'Predictive modelling of combustion-induced mechanical property degradation of flame-retardant composite structures,' funded jointly by the Engineering and Physical Sciences Research Council under Grant No. EP/D000734/1 and DSTL-MoD (Ministry of Defence), UK under the Joint Grant Scheme (Dstl/06/JGS/998,999). The University of Bolton authors thank Dr John Milnes for technical support while Hexcel's technical support is also gratefully acknowledged.

\section{References}

1. A.P. Mouritz, S. Feih, E. Kandare, Z. Mathys, A.G. Gibson, P. Des Jardin, S.W. Case, B.Y. Lattimer. Review of fire structural modelling of polymer composites. Compos. Part A: Appl. Sci. Manuf. 40 (2009) 1800-1814.

2. B.K. Kandola, E. Kandare. Composites having improved fire resistance. In Eds, A.R. Horrocks, D. Price D. Advances in Fire Retardant Materials. (2008) Woodhead Publishers, UK.

3. Y. Bai, T. Keller. Modeling of mechanical response of FRP composites in fire. Compos. Part A: Appl. Sci. Manuf. 40 (2009) 731-738.

4. Y. Bai, T. Keller, T. Vallée. Modeling of stiffness of FRP composites under elevated and high temperatures. Compos. Sci. Technol. 68 (2008) 3099-3106.

5. Y. Bai, T. Keller. Modeling of strength degradation for fiber-reinforced polymer composites in fire. J. Compos. Mater. 43. (2009) 2371-2385.

6. A.G. Gibson, Y.S. Wu, J.T. Evans, A.P. Mouritz. Laminate theory analysis of composites under load in fire. J. Compos. Mater. 40 (2006) 639-658.

7. A.G. Gibson, P.N.H. Wright, Y.S. Wu, A.P. Mouritz, Z. Mathys, C.P. Gardiner. The integrity of polymer composites during and after fire. J. Compos. Mater. 38 (2004) 1283-1307.

8. N. Dodds, A.G. Gibson, D. Dewhurst, J.M. Davies. Fire behaviour of composite laminates. Compos. Part A: Appl. Sci. Manuf. 31 (2000) 689-702. 
9. A.P. Mouritz, Z. Mathys, C.P. Gardiner. Thermomechanical modelling the fire properties of fibrepolymer composite. Compos. Part B: Eng. 35 (2004) 467-474.

10. S. Feih, Z. Mathys, A.G. Gibson, A.P. Mouritz. Modelling the tension and compression strengths of polymer laminates in fire. Compos. Sci. Technol. 67 (2007) 551-564.

11. S. Feih, A.P. Mouritz, Z. Mathys, A.G. Gibson. Tensile strength modelling of glass fiber polymer composites in fire. J. Compos. Mater. 41 (2007) 2387-2410.

12. A.G. Prodromou, S.V. Lomov, I. Verpoest. The method of cells and the mechanical properties of textile composites. Compos. Struct. 93 (2011) 1290-1299.

13. D.S. Ivanov, S.V. Lomov, S.G. Ivanov, I. Verpoest. Stress distribution in outer and inner plies of textile laminates and novel boundary conditions for unit cell analysis. Compos. Part A: Appl. Sci. Manuf. 41 (2010) 571-580.

14. C.E. Hage, R. Younès, Z. Aboura, M.L. Benzeggagh, M. Zoaeter. Analytical and numerical modeling of mechanical properties of orthogonal 3D CFRP. Compos. Sci. Technol. 69 (2009) 111116.

15. M.J. Pindera, H. Khatam, A.S. Drago, Y. Bansal. Micromechanics of spatially uniform heterogeneous media: A critical review and emerging approaches. Compos. Part B: Eng. 40 (2009) 349-378.

16. A.A. Pelegri, D.N. Kedlaya. Design of composites using a generic unit cell model coupled with a hybrid genetic algorithm. Compos. Part A: Appl. Sci. Manuf. 39 (2008) 1433-1443.

17. S.V. Lomov, D.S. Ivanov, I. Verpoest, M. Zako, T. Kurashiki, H. Nakai, J. Molimard, A. Vautrin. Full-field strain measurements for validation of meso-FE analysis of textile composites. Compos. Part A: Appl. Sci. Manuf. 39 (2008) 1218-1231.

18. J. Lua. Thermal-mechanical cell model for unbalanced plain weave woven fabric composites. Compos. Part A: Appl. Sci. Manuf. 38 (2007) 1019-1037.

19. A. Drago, M.J. Pindera. Micro-macromechanical analysis of heterogeneous materials: Macroscopically homogeneous vs. periodic microstructures. Compos. Sci. Technol. 67 (2007) 12431263. 
20. A. Miravete, J.M. Bielsa, A. Chiminelli, J. Cuartero, S. Serrano, N. Tolosana, R.G. de Villoria. 3D mesomechanical analysis of three-axial braided composite materials. Compos. Sci. Technol. 66 (2006) 2954-2964.

21. P. Tan, L. Tong, G.P. Steven. Modelling for predicting the mechanical properties of textile composites: A review. Compos. Part A: Appl. Sci. Manuf. 28 (1997) 903-922.

22. S. Li. On the unit cell for micromechanical analysis of fibre-reinforced composites. Proc. Roy. Soc. Lond. A 455 (1999) 815-838.

23. E. Weissenbek, H.J. Bohm, F.G. Rammerstorfer. Micromechanical investigations of arrangement effects in particle reinforced metal matrix composites. Comput. Mater. Sci. 3 (1994) 263-278.

24. S. Li, A. Wongsto. Unit cells for micromechanical analyses of particle-reinforced composites. Mech. Mater. 36 (2004) 543-572.

25. S. Li. General unit cells for micromechanical analyses of unidirectional composites. Compos. Part A: Appl. Sci. Manuf. 32 (2001) 815-826.

26. S. Li, S.H. Lim. Variational principles for generalized plane strain problems and their applications. Compos. Part A: Appl. Sci. Manuf. 36 (2005) 353-365.

27. ABAQUS Analysis User's Manual, Version 6.5 (ABAQUS Inc., Providence, RI, 2004).

28. A. Wongsto, S. Li. Micromechanical FE analysis of UD fibre-reinforced composites with fibres distributed at random over the transverse cross-section. Compos. Part A: Appl. Sci. Manuf. 36 (2005) 1246-1266.

29. H.Z. Li, S.G. Li, Y.C. Wang. Prediction of effective thermal conductivities of woven fabric composites using unit cells at multiple length scales. J. Mater. Res. 26 (2011) 384-394.

30. S. Li. Boundary conditions for unit cells from periodic microstructures and their implications. Compos. Sci. Technol. 68 (2008) 1962-1974.

31. E. Kandare, B.K. Kandola, P. Myler, G. Edwards. Thermo-mechanical responses of fiber-reinforced epoxy composites exposed to high temperature environments. Part I: experimental data acquisition. J. Compos. Mater. 44 (2010) 3093-3114.

32. E. Kandare, B.K. Kandola, E.D. MaCarthy, P. Myler, G. Edwards, J.F. Yan, Y.C. Wang. Fiber- 
reinforced epoxy composites exposed to high temperature environments. Part II: modeling mechanical property degradation. J. Compos. Mater. 45 (2011) 1511-1521.

33. A.I. Shutov, A.G. Shabanov, Y.L. Belousov, V.A. Firsov. Method of determining the elastic modulus of glass at temperatures above the vitrification temperature. Glass and ceramics 48 (1991) 143-144. 
Figure 1. a) Finite Element-meshed rhombic dodecahedron; Unit Cell 1 and b) a view of the inside quarter of the unit cell.

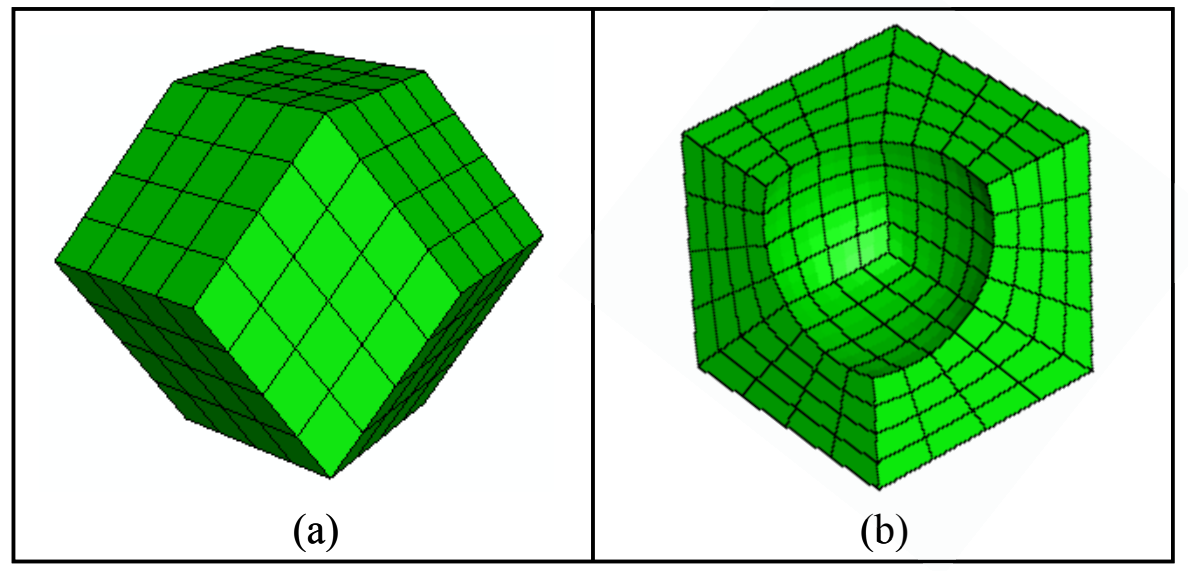

Figure 2. Finite Element-meshed idealized hexagonally-packed Unit Cell 2 for glass fibre yarns.
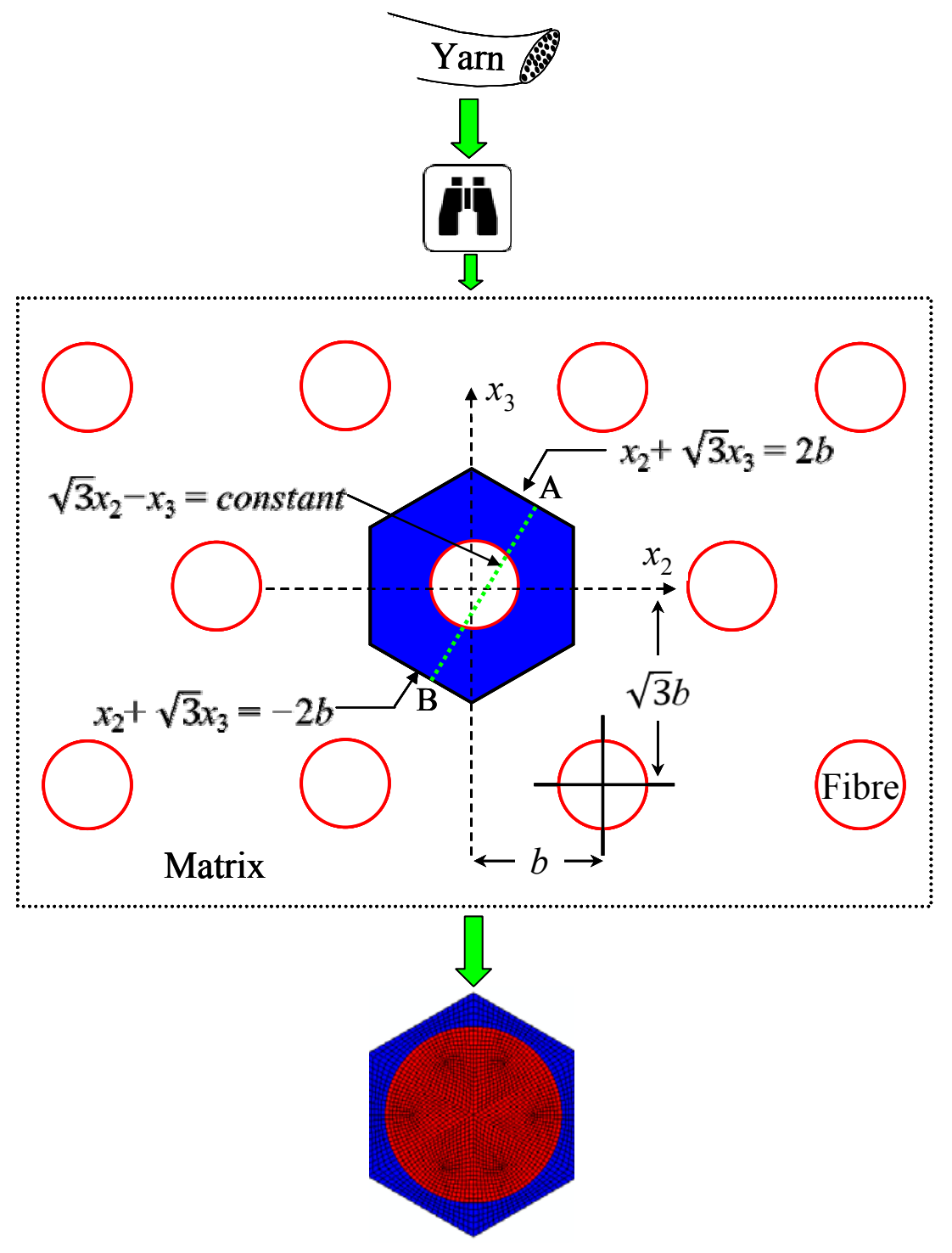
Figure 3. Flow-chart diagram for the construction of a woven fabric laminate composite: Unit Cell 3.

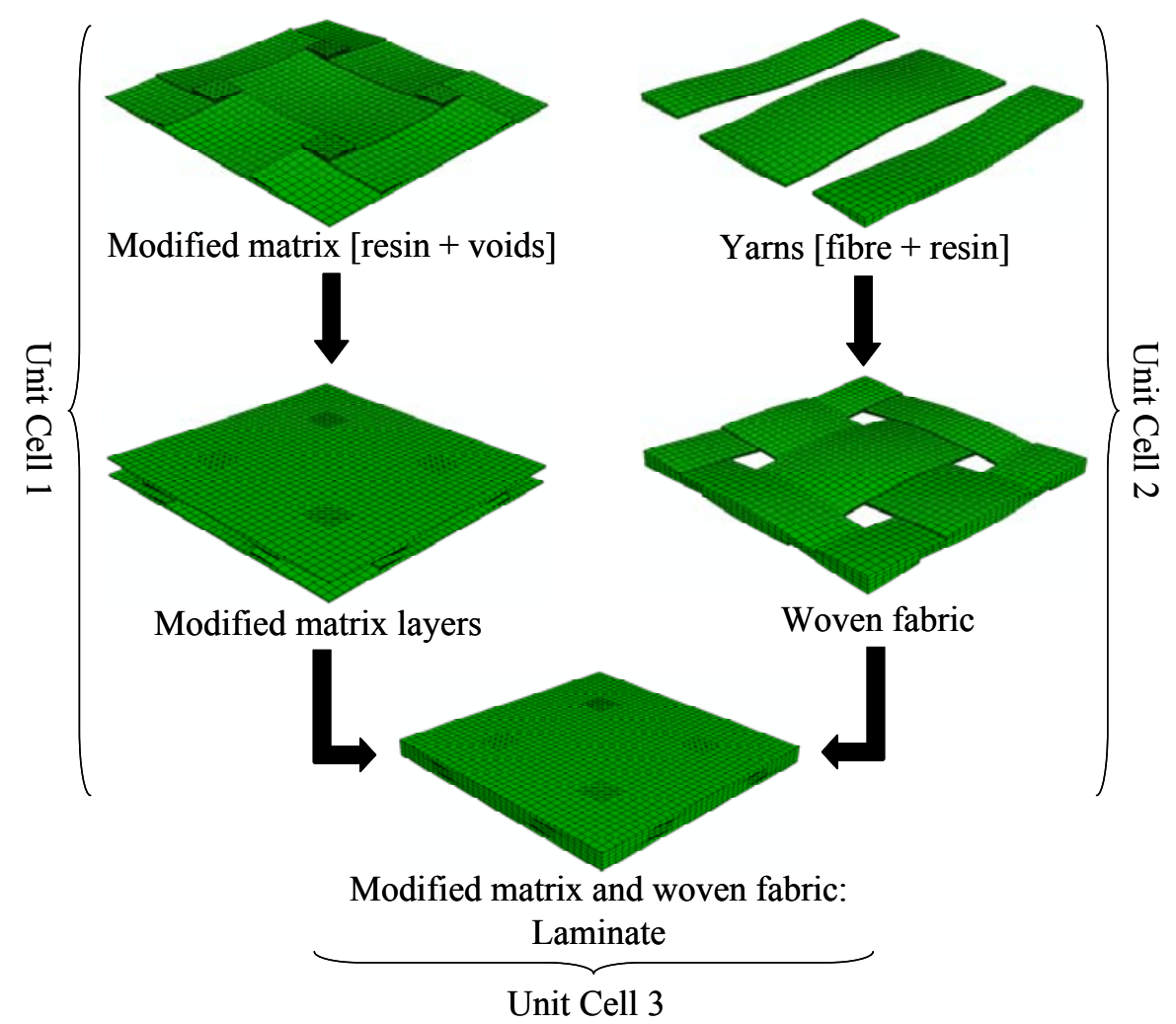

Figure 4. Cuboid-shaped Unit Cell 3 and its geometric dimensions.

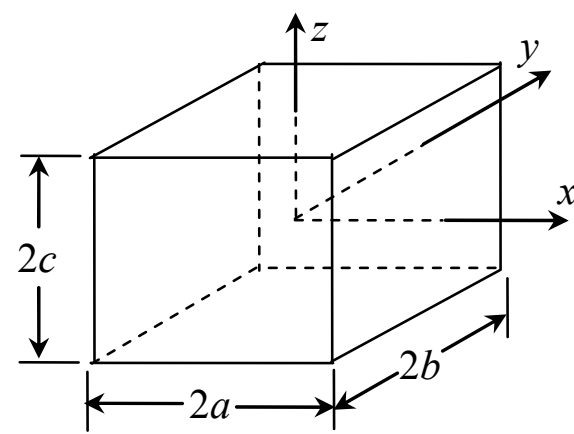


Figure 5. Illustration of the geometric representative parameters of the woven yarns constructed using data acquired via the scanning electron microscopy.

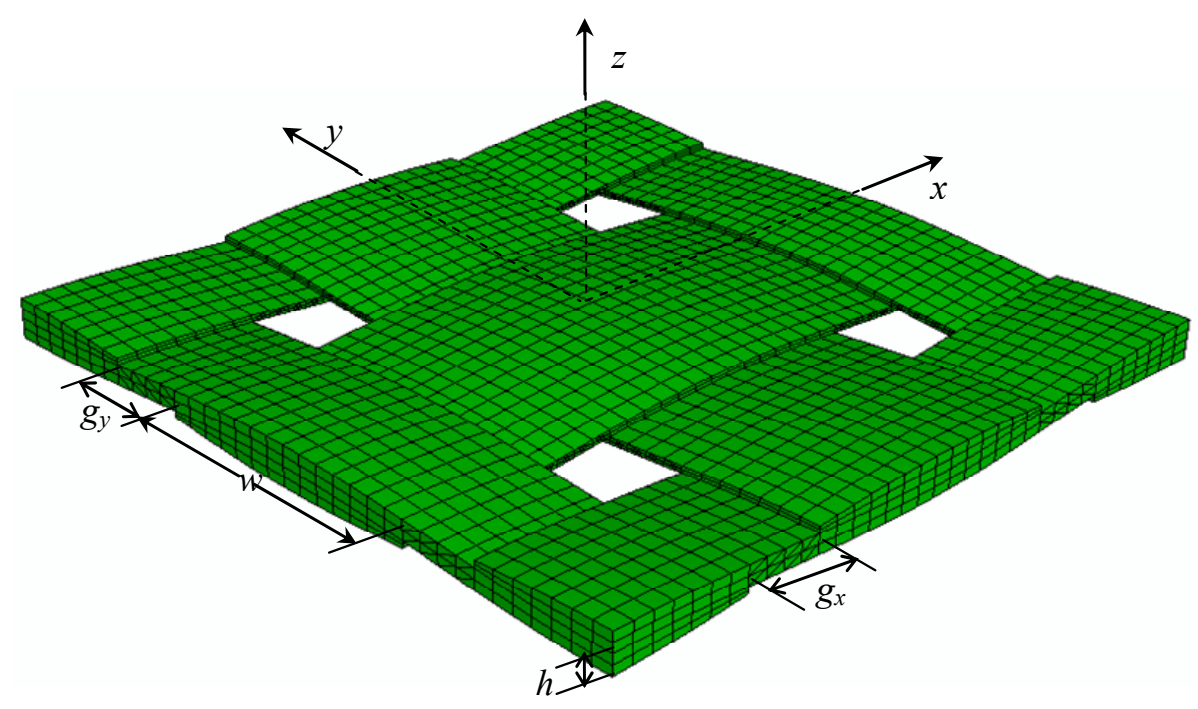

Figure 6. A close-up of the FE mesh of the fill/warp yarn gap-filling resin matrix in Unit Cell 3.

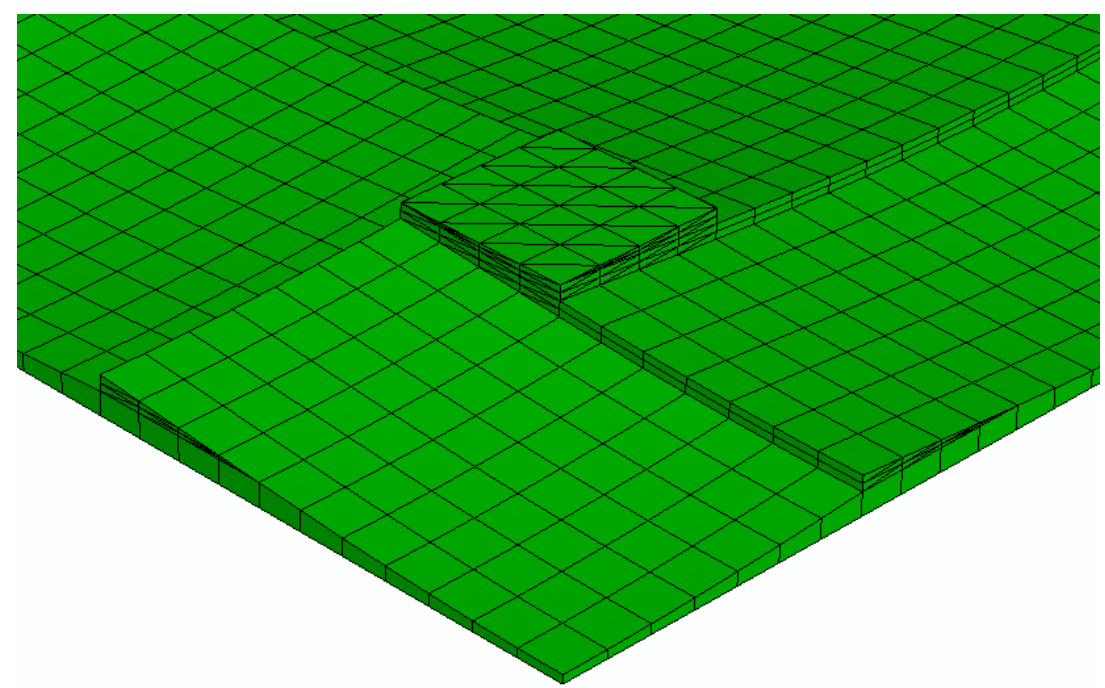


Figure 7. Experimental flexural moduli at selected temperatures for (a) unmodified cast epoxy resin and (b) glass fibre-reinforced composites with/without fire retardant additives. The solid lines in (a) and (b) are fitted using equation (13).
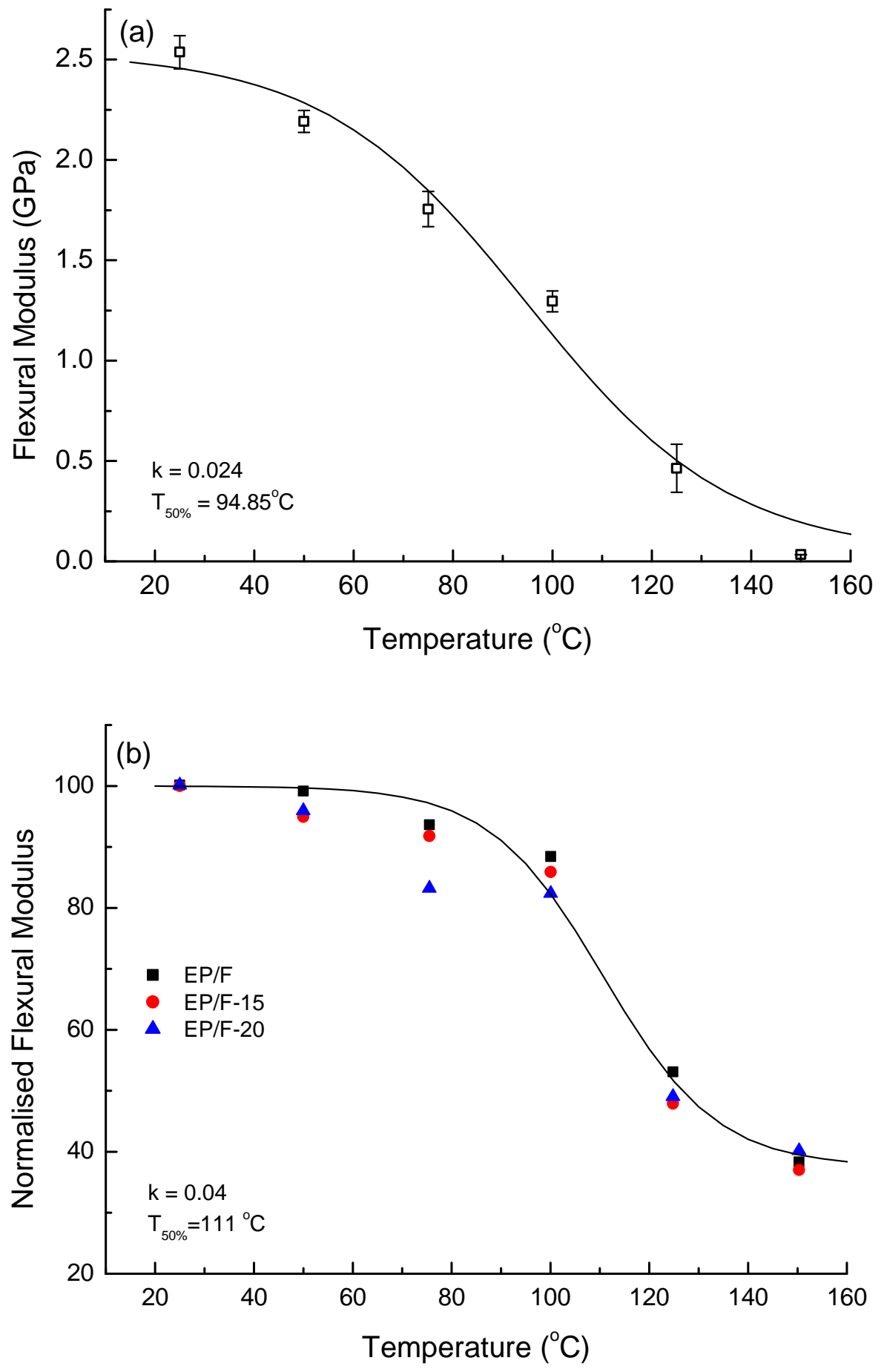
Figure 8. Comparison of measured and predicted flexural moduli of glass fibre-reinforced composites with/without fire retardants at elevated temperature. The dashed line represents the equation $\mathrm{x}=\mathrm{y}$.

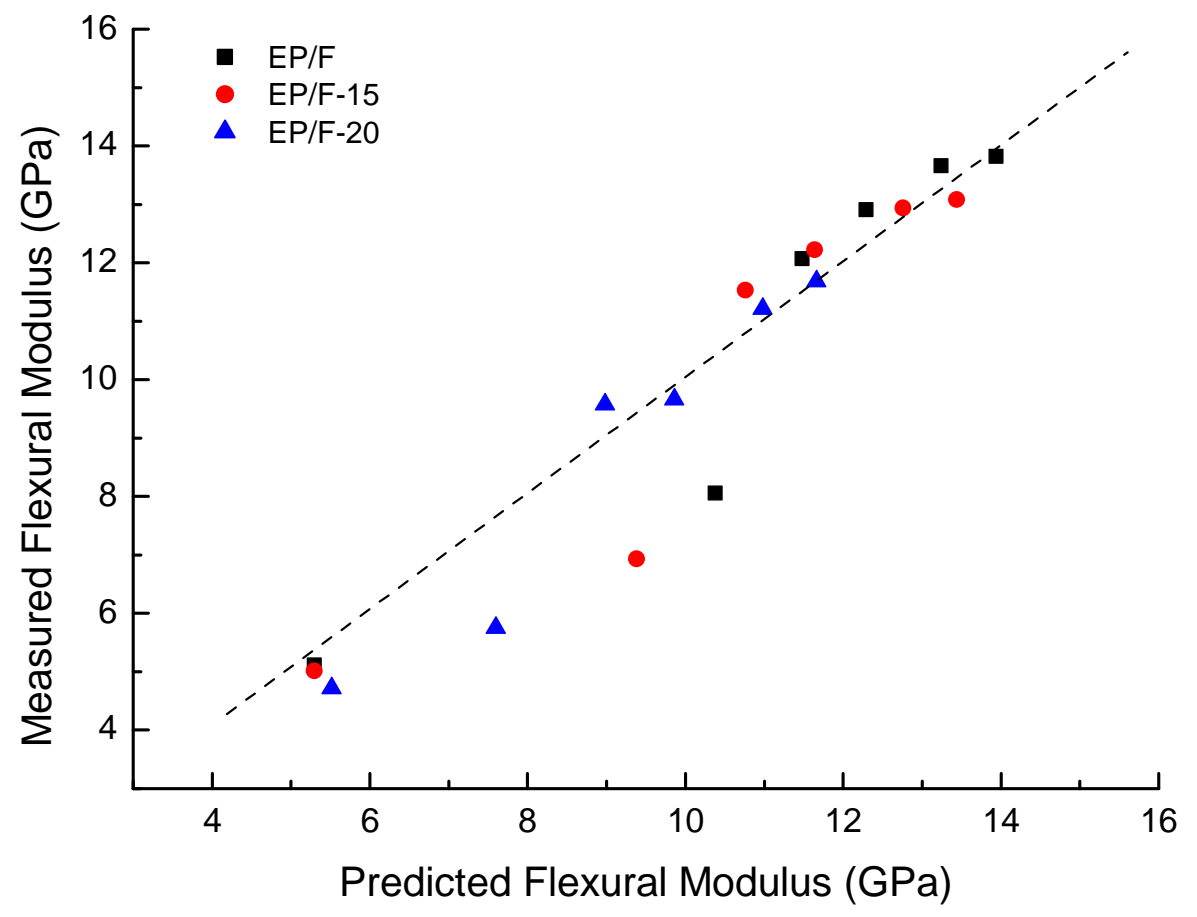

Figure 9. Predicted effective material properties as a function of temperature for woven fabric composite with/without fire retardants: (a) transverse elastic moduli, (b) transverse and in-plane Poisson's ratios, (c) shear moduli.

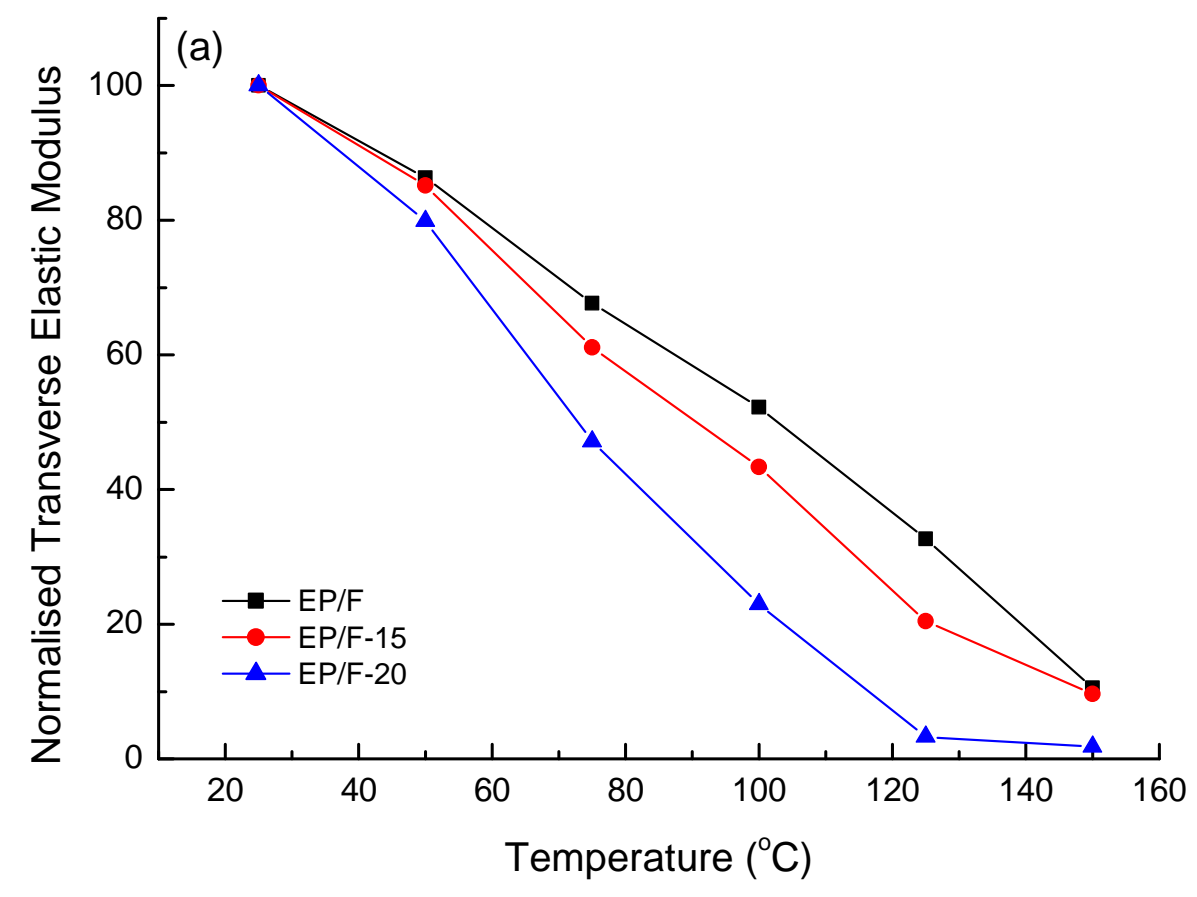



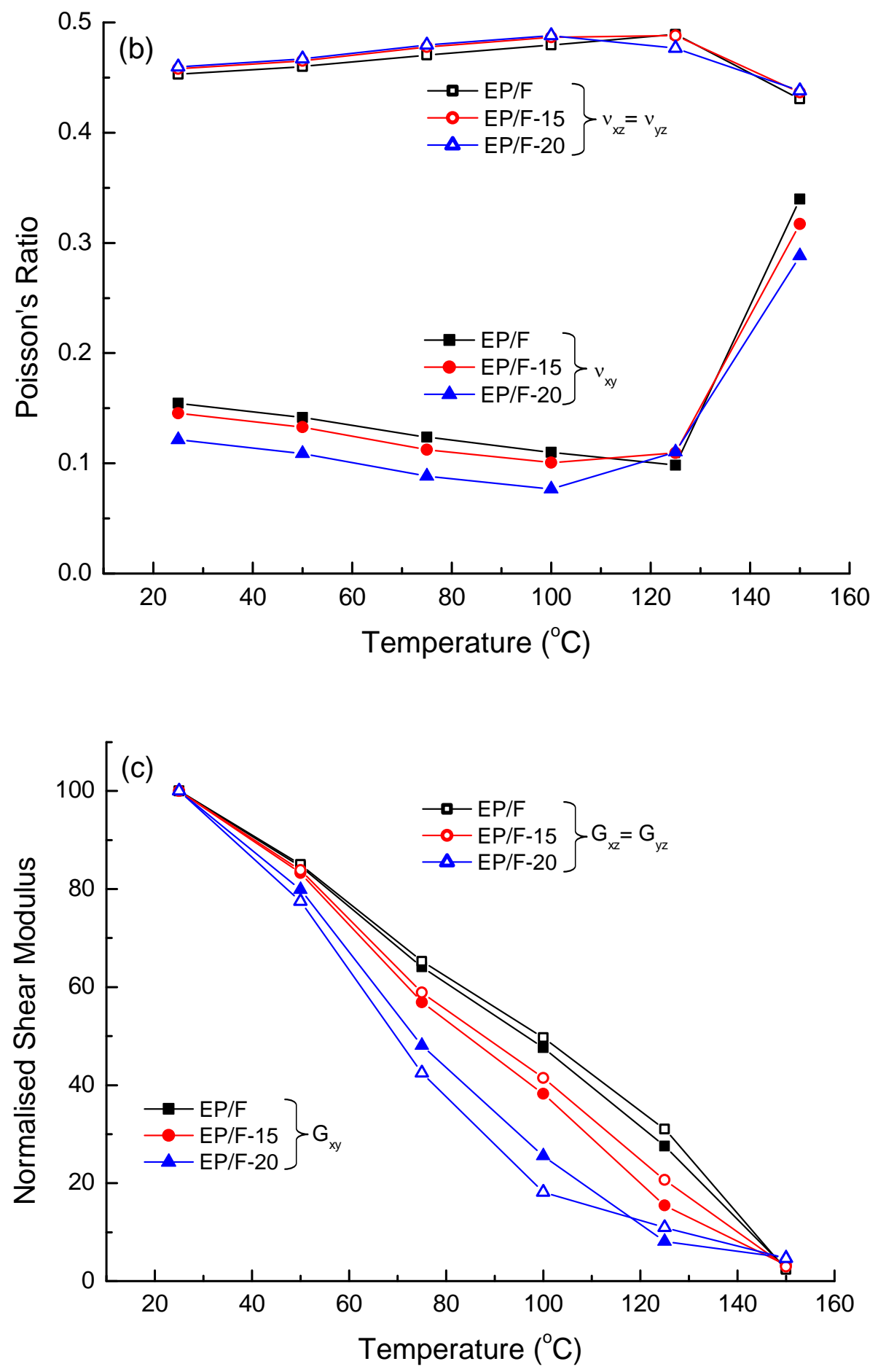